\title{
Disputing nature in the Anthropocene: technology as friend and foe in the struggle to conserve wild Atlantic salmon (Salmo salar)
}

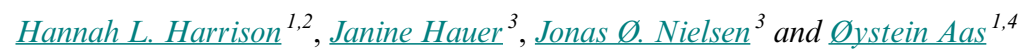

\begin{abstract}
The Anthropocene, simply put, is characterized by the recognition that natural processes are inextricably entwined with human influence. Against this backdrop, managing natural resources needs to be fundamentally rethought as balancing human-nature entanglements continues to challenges policymakers and conservation managers obligated toward politically and scientifically feasible measures. A closer look at wild Atlantic salmon management in Europe reveals dynamic shifts over the past two centuries, particularly with regard to how hatcheries are used as conservation tools. We use case studies on Norwegian and Welsh wild salmon cultivation practices to trace these shifts in conservation and management practices. We frame our analysis through a lens of shifting conceptualizations of naturalness and human-salmon relationships. Starting at the multinational level and then moving to groundlevel cases, we show how naturalness is conceptualized by managers and hatchery stakeholders, and how those perceptions play into definitions of desired outcomes for wild salmon conservation as well as the strategies and technologies implemented to achieve these conservation goals. We highlight two paradoxes that are illuminated by the disputes and shifting perceptions surrounding salmon hatcheries. First, we show that hatcheries are no longer perceived as appropriate tools to increase wild salmon populations. Rather, hatchery technologies are being withdrawn, limited, or transformed, often resulting in local-level controversy. Paradoxically, these changes are, in themselves highly technical processes involving genomic testing and big data inventories. Second, despite the recognition of ever more complex human-nature entanglements, the practical outcomes for salmon conservation are oriented toward standardized testability and manageability and limiting certain human-salmon interactions, and although some technologies are instrumental, others are disregarded. As a result, those techno-social communities organized around hatchery technologies are at risk of being removed or otherwise excluded from their preferred conservation activities.
\end{abstract}

Key Words: Atlantic salmon; conservation technologies; hatcheries; nature; Salmo salar; techno-social;

\section{INTRODUCTION}

Atlantic salmon (Salmo salar) hatcheries were originally multipurpose tools intended to mitigate negative impacts to salmon habitat and spawning grounds after mainly anthropogenic events and improve upon the perceived inefficiencies of nature by offering fishers an opportunity to pursue greater numbers of prey (Bottom 1997). Hatcheries thus represent a technological approach to approximating and, in some cases, augmenting existing stocks and compensating for human-caused damage to salmon environments (Berg 1986, Cronon 1995, Lorenzen et al. 2013). Combined with continued stakeholder support for stocking (Arlinghaus and Mehner 2005, Stensland 2012), these dual purposes made hatcheries a widespread and governmentapproved management tool in Europe and North America during the nineteenth and twentieth centuries (Berg 1986, Bottom 1997, Wolter 2015).

Despite this popularity, advancement in the scientific understanding of genetics and evolutionary ecology has raised concerns about the potential negative impacts of stocking on wild fish populations. Hatchery critics are particularly concerned that hatchery fish may outcompete or outnumber their wild counterparts (Swain and Riddell 1990, Jonsson and Jonsson 2006, Blanchet et al. 2008) and the potentially deleterious effects of cross-breeding on the genetic integrity of wild populations (Garcia de Leaniz et al. 2007, Laikre et al. 2010). Specifically, those effects could narrow genetic diversity among wild salmon populations (Garcia de Leaniz et al. 2007, Naish et al. 2007, Araki and Schmid 2010), and in the long term could potentially produce fish maladapted to the natural environment (Henderson and Letcher 2003, Araki et al. 2007). Although some efforts have been made to try to improve hatcheries to mitigate these effects and produce better outcomes for hatchery-reared salmon (Paquet et al. 2011, Mes 2018), concerns about the negative effects of hatchery fish introduced into wild fish populations have led to the restriction and, in some cases, closure of hatchery and stocking programs altogether, causing conflict between cultivation stakeholder groups (Harrison et al. 2019).

These changes in scientific understanding of salmon management and conservation have also contributed to how the debate over what a "good" salmon is and how that quality should be defined in conservation, has changed. Whereas hatcheries have previously been viewed as highly adequate tools to compensate for destructive human impacts on salmon habitat, today they are increasingly considered producers of an unnatural salmon: a nonwild or "hatchery-type" fish (NASCO 2017). Previously, it was sufficient for hatchery-produced fish to be qualitatively wild; to look, taste and behave like a wild salmon (Scarce 2000). Now, a growing body of research suggests that when stocked into naturally recruiting populations, hatchery-reared fish can produce undesirable outcomes for wild stocks, such as disease transmission (Hewlett et al. 2009), negative competitive interactions with wild progeny and reduction of effective wild population size (Chilcote et al. 2011), and negative impacts on the genetic integrity and diversity of local genetic populations

\footnotetext{
${ }^{1}$ Norwegian University of Life Sciences (NMBU), Faculty of Environmental Sciences and Nature Management (MINA), Norway, ${ }^{2}$ University of Guelph, Department of Geography, Environment, and Geomatics, and the Arrell Food Institute, Guelph, Ontario, Canada, ${ }^{3}$ Humboldt-Universität zu Berlin, IRI THESys and the Department of Geography, Berlin, Germany, ${ }^{4}$ Norwegian Institute for Nature Research (NINA), Lillehammer, Norway
} 
and subpopulations (Laikre et al. 2010). This improved scientific understanding of salmon cultivation has turned the tide of scientific and, more recently, managerial opinions toward requiring genetically "natural" instead of qualitative "natural" salmon.

We introduce two cases and sketch the historical development of hatcheries in Wales and Norway with regard to how humannature relationships were conceptualized and facilitated over time. We ask: how do stakeholders conceptualize and construct naturalness in the context of salmon hatcheries? Based on these understandings, how are hatchery technologies being understood and (dis)allowed as tools within salmon conservation, and do these technological thresholds of evaluating salmon naturalness impact the inclusion of salmon conservation stakeholders in these cases? Finally, we grapple with the effect of changing understandings of naturalness and how they are used to arbitrate appropriate conservation technologies for the techno-social communities in these cases.

The term natural and its derivatives (i.e., naturalness, etc.) are popularly used across disciplines to describe desirable natural resource management objectives (Haydon 1997, Scarce 2000), often alluding to a state of nature free from human impacts, influence, or presence (Hendee et al. 1978). Though subject to manifold definitions, the shifts we trace in this study are concerned with how relationships between humans and, in this case, salmon, are considered and permitted. Human intervention in salmon lives via hatcheries has long been a politically and managerially prioritized means of compensating for destructive human impacts on salmon habitats. Improved scientific understandings of salmon biology, physiology, ecology, and genetics have changed this priority and created new boundaries for acceptable salmon genotypes and phenotypes, the definition of which are heavily science- and technology-dependent and represent ideals of wildness situated within conservationist culture and manifested by technology (Milton 2000).

Recent guidelines from the intergovernmental North Atlantic Salmon Conservation Organisation (NASCO) reflect that managers of salmon stocking projects and scientists view genetic and ecological naturalness as a top management priority (NASCO 2017). North Atlantic Salmon Conservation Organisation is an intergovernmental organization based on a shared treaty with direct influence over its member states' salmon management policies. Its objectives are to "conserve, restore, enhance and rationally manage Atlantic salmon through international cooperation taking account of the best available scientific information" (www.nasco.int/about.html). Concepts of naturalness are linked closely with scientific knowledge about salmon genetics, ecology, and reproduction, and are paired with discussions about which technologies are appropriate for enacting salmon conservation toward wild salmon genotypes. Because these perceptions are intermingled with a growing scientific consensus on the potential harms of stocking, policymakers and managers at the local, national, and international level have turned away from hatcheries because of concerns that they produce salmon with reduced fitness than wild conspecifics. In practice, this shift has resulted in stricter stocking guidelines, and in some cases the introduction of controversial restrictions and closures of existing stocking projects (Harrison et al. 2018a, $b$ ). Our analysis shows how the definitions of wild, natural, or "good" ("right") salmon are situated across stakeholder groups, and how their contrasting positions may influence disagreement about the use of salmon hatcheries in conservation. Our analysis also sheds light on the specific roles that technology performs in salmon conservation and management and highlights how technology is seen as both cause and solution for challenges to wild salmon conservation.

We embed our analysis of these shifts in the broader discussions of the Anthropocene, adding to an ongoing discussion of salmon conservation in this era (Daniels and Mather 2017a, b). The Anthropocene is characterized by the recognition that natural processes, which once occurred independently from human influences, are inextricably entwined with human life. Against this backdrop, managing natural resources should include nuanced considerations of human-nature entanglements and, as in these cases, the entwining of conservation technologies with preexisting social-ecological systems (Berkes et al. 2008, Ban et al. 2013). Effectively managing human-nature entanglements poses a challenge to policymakers and conservation managers who must balance the prioritization of biodiversity and ecosystem management with stakeholder needs and economic and social constraints. In doing so, we look at how these challenges are being dealt with through more testable and definable means of evaluating nature, and how these means of nature definition rely upon increasingly complex technologies.

We examine the tension occurring within both cases between the shared recognition of complex human-nature entanglements in salmon management and the practical need to implement measures of governing conservation goals. We are interested in understanding how hatchery technologies and their associated techno-social systems are dealt with in the complex salmon systems. We identify the multiple ways in which human-salmon entanglements are thought of and managed in both cases, particularly through the assessment and institutionalization of appropriate and inappropriate salmon conservation technologies. We argue that though managing and reducing complexity are necessary in salmon conservation, a careful consideration of situated approaches and ontological positioning on concepts such as nature and naturalness need to be incorporated into advising on natural resource management issues.

\section{METHODS}

This study draws on fieldwork conducted among and within salmon cultivation settings in April, May, and June of 2016 in Sunnmøre, Norway and the Wye Valley, Wales. The study is part of a larger research program on small-scale salmon hatcheries (see Harrison et al. 2018a, $b$ ). The main methods used during fieldwork were semistructured interviews with fisheries managers, fisheries scientists from predominant Norwegian and Welsh research institutes (i.e., Norwegian Institute for Nature Research, Norwegian University of Science and Technology, and Natural Resources Wales), river owners, angling society members and club leaders, hatchery operators and volunteers, and casual anglers unassociated with clubs or hatchery operations. The first author also engaged in participant observation to gain important insights into the practices and personal experiences of hatchery operators, anglers, and managers. Participant observation was conducted in hatcheries (Norway only) and river monitoring/observation work. Site visits (go-alongs; Kusenbach 2003) were also made to closed 
hatcheries (Wales only), important angling locations, or other sites of salmon conservation interest. These visits were conducted to gain a broad picture of the salmonscapes and to inform the researchers about the nature of locations or activities described in interviews, as well as to build rapport with interview participants and allow space for casual, informal conversations about research topics (Evans and Jones 2011).

Interview participants were identified using the key informant method (Marshall 1996) as well as through purposive sampling (Palys 2008) in an effort to interview those knowledge holders directly engaged with hatchery activities. In total, interviews with 45 individuals were conducted across both cases. All interviews were conducted in English and either with individuals or in small groups if desired by the interviewee. Interviews typically lasted between 60-180 minutes and were recorded and later transcribed. Questions were intentionally open ended and interview participants were encouraged to share relevant information and stories to allow the introduction of topics not previously anticipated by the data collection team.

Because Norwegian interview participants gave the interview using English as a second language, we did not take literally terms like nature, naturalness, wild, and like terminology unless specified by the interview participant. Rather, we analyzed statements referencing a desired state of salmon characteristics, paying close attention to the context of comments. Thus, conceptualizations of nature emerged from the interview data as descriptions, which we then analytically termed and categorized as discussions of nature and naturalness. We compared interview findings to a similar textual analysis on guiding policy documents and stocking guidelines from international- and national-level publications.

The relevant policy documents that frame the work of the hatchery operators and inform the broader debates among stakeholders were analyzed. Specifically, we analyzed the 2017 report of a theme-based special session entitled Understanding the Risks and Benefits of Hatchery and stocking Activities to Wild Atlantic Salmon Populations (NASCO 2017), which was written as part of a NASCO theme-based special session on stocking. This document was selected to form an internationally scoped view of how scientific and managerial communities now view salmon hatcheries and stocking practices in Norway and Wales. It frames and informs all hatchery-related rules and regulations in both cases top-down. This report was analyzed through a naturalness lens by attending to how language surrounding naturalness conceptualizations was used (e.g., wild, natural, artificial, etc.) by the report authors (some of whom are also managers within these cases), and the lines of argument created in each report to support or reject stocking practices or offer guidance toward naturalizing hatchery practices.

All data were analyzed using qualitative data analysis software packages Atlas. Ti (Scientific Software Development 1999, Paulus and Lester 2016) and NVivo (QSR International Pty Ltd. 2012). Data were first analyzed by the first author using a thematic coding approach. Once an initial set of themes was identified within the topic area, several more rounds of itinerant coding were conducted to refine the coding scheme and draft memos on the emerging themes. The findings of this process were discussed between the first and second authors, further refined through additional questioning of the data, then discussed again within the entire author team to check the inductive reasoning behind code and theme identification and the rationale behind explanations arising from the analysis.

\section{Case backgrounds}

River Wye, Wales

Since the early 1900s, a series of hatcheries and stocking projects have been established. Aside from early compensatory stocking projects, hatcheries on the Wye have been built as a means of supporting the existing fishery during periods of low returns and to conserve remaining wild populations by overcoming reproductive and early life-stage bottlenecks to salmon survival within the relative safety of the hatchery.

Salmon form a central piece of the River Wye's character (Gilbert 1929, Hurley 2008), and management and conservation of this species have frequently been a topic of debate. Efforts to improve and conserve wild salmon runs in the Wye have been attempted over the past several centuries via antipoaching campaigns, harvest regulations, cultivation efforts, and most recently catchment-scale habitat improvement efforts. Of these efforts, hatcheries have been a particularly contentious aspect of the salmon conservation debate since the 1990s.

Wye salmon hatcheries were initially instituted as a compensation measure for dams, indicating beliefs that the right science and technologies could compensate, at least in part, for human damage to the environment (Lamont 1990, Haydon 1997). This trend is reflective of attitudes of "techno-arrogance"(Meffe 1992) or the belief that innovative technologies can overcome environmental damage. Thus, the introduction of hatcheries on the Wye marks a point in which hatcheries fit into paradigms of nature as an aid to repair (or improve upon) naturalness disrupted by human interventions. Importantly, hatcheries in this period are aimed at achieving qualitative naturalness. That is, they produce salmon that look and behave similarly to wild fish (Scarce 2000). With the limited scientific understanding of salmon physiology and ecology of the day, hatchery-produced fish were viewed as a more natural outcome than the reduction or absence of fish entirely.

In 2012, a new approach to salmon cultivation was initiated by a collaboration of river owners and anglers: seminatural rearing ponds (SNR). The SNR ponds were intended as a means of providing a less artificial rearing ground for juvenile salmon in which they could learn foraging behaviors and undergo a reduced degree of selection (in comparison to wild fish) while still benefiting from a protected environment. This initiative was a response to growing pressure to conduct hatchery and stocking projects in more standardized and scientifically sound ways, particularly with respect to the threat of genetic introgression of hatchery-type fish on wild fish populations (Laikre et al. 2010). This shift marks a distinct change in understanding of what a desirable Wye salmon should be and how it should be produced. The SNR pond initiative (an initiative funded primarily by private contributions, and hatcheries in both Norway and Wales were funded by a combination of private, club, and government contributions) was matched with an agreement between pond supporters and Environmental Agency Wales (EAW, Natural Resource Wales' (NRW) predecessor) to conduct a 10-year study on the hatchery/pond-raised fish to properly assess the effectiveness of such a stocking effort. Although the cost of 
hatchery and stocking projects is relevant to management of the hatcheries in these case studies, this issue was not a primary driver within the discussions of nature, naturalness, and scientific understanding of salmon conservation.

At the same time as the SNR project was getting underway, an evaluation of stocking in Wales was found contraindicative to the main statutory and principal requirements that govern the UK's salmon resources, notably the Habitats Directive (EEC 2000), Precautionary Principle (Jordan and O'Riordan 1995), the Ecosystems Approach (Convention on Biological Diversity 1995) as well as guidelines set by NASCO's Williamsburg Resolution (NASCO 2007). After a hotly contested public consultation period, NRW ended all stocking in Wales in 2014 with the exception of some research-based projects. In 2015, the last remaining SNR pond salmon were released into the Wye, thus inconclusively ending the associated study.

\section{Orsta River, Norway}

In 1931, when the first Ørsta hatchery was built along a forested stretch of the Åmdalselva (Aam 2009), it joined a long practice of local salmonid hatcheries along the Norwegian coast (Svåsand et al. 2004). It was first constructed as an enhancement measure during a wave of hatchery building in the Sunnmøre region. At the time, salmonid hatcheries were used to improve fishing and harvesting opportunities, a scheme that was strongly supported by the state-level salmon management organization of the time (Statens Fiskeetat; Aam 2009, Berg 1986). The original Ørsta hatchery used Ørsta River water to hatch and raise salmon parr, a deliberate choice intended to recreate their natural condition (i.e., river water) within the artificially safe rearing habitat of the hatchery. This design choice reflects thinking at the time that prioritized maintaining the natural conditions of the river as a way of improving the quality of hatchery-reared fish.

This hatchery was used on-and-off throughout the 30 s and 40 s, interrupted by World War II and poor fishing years when insufficient broodstock could be captured to stock the hatchery with fertilized eggs. In the 1950s, the fishing community began to stabilize again, and the local hunting and fish club was established, a group who restarted cultivating in 1953-54. Throughout Norway, a new wave of fish cultivation began as part of the effort to rebuild Norwegian food security (Aam 2009). As part of this effort, the Ørsta River was straightened and the existing Ørsta hatchery transitioned from a salmon stock enhancement tool to a compensatory tool.

In the 1960 s, a new hatchery was built to compensate for the sediment and debris-filled water that inundated the hatchery during floods and led to fish kills. This hatchery is still in use today and produces annual broods of salmon and brown trout, which are stocked within the Ørsta River watershed. In 2014, a new set of guidelines was released (Norwegian Environment Agency 2014) based on recommendations concerning salmon stock enhancement produced by NASCO (NASCO 2006) that initiated a review of stocking practices and regulations in Norway. Among other demands, the new guidelines required all broodstock used in voluntary hatcheries to be genetically tested to exclude escaped farmed fish and their descendants from being used as reproductive material donors to avoid introgression of domestic conspecifics on wild stock genetic diversity. This change in stocking guidelines reflects an institutionalized shift in attitudes toward which salmon are and are not appropriate for wild stocks, as well as offers clues as to how hatchery technologies and their operators are being directed to conduct hatchery operations to minimize risks to the adaptation of recipient populations to natural environments. In doing so, the guidelines are inherently setting definable limits around what constitutes a natural or wild fish.

\section{RESULTS}

\section{Nature in salmon policy}

The study, regulation, and management of Atlantic salmon begins at the international level where major international organizations contribute toward developing policies, guidelines, and recommendations for wild salmon management based on best scientific advice (NASCO, International Council for the Exploration of the Sea, etc.). Thus, we began our analysis at this level so as to build a contextual background in which to understand and compare local-level stakeholder perspectives.

North Atlantic Salmon Conservation Organisation is a key organization to which individual countries with interest in wild salmon conservation have become party, agreeing to contribute toward and abide by the recommendations released by NASCO. With regard to Atlantic salmon stocking, the Williamsburg Resolution is a key resolution that directs NASCO member states to minimize the impacts of stocked fishes on wild fish populations (NASCO 2007) with particular attention to the negative impacts of stocking on genetic integrity of wild stocks.

As part of the ongoing work directed by the Williamsburg Resolution, the 2017 report entitled Understanding the Risks and Benefits of Hatchery and Stocking Activities to Wild Atlantic Salmon Populations (2017) was written to report on best practices and facilitate knowledge exchange related to the risks and benefits of hatchery and stocking activities to wild Atlantic salmon populations (NASCO 2017). The report consists of several individual reports authored by wild salmon managers, scientists, and hatchery regulators, including managers from Norway and Wales. These experts' viewpoints and evaluations offer a unique summary of the different positions toward the use and challenges of hatcheries as conservation tools. As such, the report allows us insights into how these managers conceptualize the relationships between nature, salmon, and hatchery technologies and, subsequently, enshrine those views into wild salmon management policy. Several sections within the report argue for defining appropriate or natural salmon, and thus the desirable salmon, through genetic considerations. More specifically, the report focuses on issues of genetic integrity and associated behavioral and physiological traits of salmon born and/or reared in hatcheries. The report contributors point out that the relaxation of natural selection or unintentional selection by humans constitute the biggest culprits of denaturalizing salmon genetics in the hatchery:

Selection of mates for crossing in hatcheries generally cannot take account of the natural spawning destination of fish. The artificial crossing decisions result in crosses highly unlikely to have occurred naturally. This overrides natural mate selection processes, placing at risk factors that preserve and protect genetic variability and adaptations and natural disease resistance (NASCO 2017:66). 
Taken as a whole, the report marks a condensed shift toward applying genetically oriented criteria toward advanced technologies for defining and identifying the appropriate, or natural, salmon in wild Atlantic salmon management. In our analysis. we identified three important themes within the report: (1) how natural processes are prioritized in salmon lives, (2) how humans should or should not be involved in salmon lives, and (3) how these ideas are couched in notions of appropriate technologies to facilitate human-salmon relationships.

Looking at the first theme, the word "naturally" in the above quotation is clearly used to delineate between pairings facilitated by humans and pairings that would have occurred without human intervention. The underlying argument is that humans have only partial knowledge of the processes by which salmon, when left unfettered by humans, make their own mating choices (Foote 1988, Landry et al. 2001, Watters 2005) and thus humans cannot precisely imitate this process. This means that hatcheries cannot properly reproduce the genetic diversity that occurs in wild salmon populations, thus "placing at risk factors that preserve and protect genetic variability and adaptations and natural disease resistance" (NASC0 2017:66). This priority is clearly seen in the Norwegian section of the report:

[t]o preserve the original population and its genetic variability, measures to remove limits on natural production (like habitat restoration) must be prioritized (NASCO 2017).

Genetic variability that occurs without human influence appears as the desirable outcome of salmon reproduction, but active restoration of existing habitat to expand production is acceptable. Preferably, the salmon itself is not to be touched by conservation methods, but rather its environment is to be targeted. Contextualizing this within changing attitudes toward hatcheries, the second theme of the report, regarding human-salmon relationships, emerges. It appears that habitat improvement efforts are still acceptable at the quantitative level, in which salmon hatchery outcomes used to be acceptable, whereas the salmon themselves must be genetically natural, a far more challenging outcome to secure. Thus, habitat improvement work appears to assume less overall risk than hatcheries to the salmon population at hand.

Regarding the third theme, the report conceptualizes naturalness to describe natural selection within the report, or how and what variables kill salmon in their juvenile stages (i.e., life stage bottlenecks). In this respect, hatcheries may be considered useful technologies used to widen life stage bottlenecks during the salmon's juvenile period. The underlying goal of more salmon reaching adulthood to spawn than occurs without technological intervention, subsequently producing a larger breeding population that can eventually reproduce without the hatchery is a clear objective of hatcheries. However, the report argues that the value of natural selection on salmon populations is paramount to the quality of those salmon that may eventually reproduce, thus indicating that how salmon live and die, rather than simply if they live or die, is an important element in determining their quality and appropriateness to the natural salmon landscape in addition to supporting biological arguments of the role of natural selection in ensuring fish fitness.
This discussion of fitness in the report, and in the wider salmon hatchery community, thus clearly touches on how ideas of nature are tied into ideas of wildness. In the report, discussions about natural selection and reproduction are limited to the confines of the hatchery. However, in both Norway and Wales, many other human technologies have an impact on the survival, behavior, and eventual reproduction (i.e., agricultural runoff, migratory barriers, catch and release recreational fisheries, impacts from commercial salmon aquaculture, etc.) of juvenile and adult wild Atlantic salmon. However, environments outside of the hatchery are frequently termed natural, i.e., natural streams, the natural environment, or natural rearing conditions by the report and our interview participants. Though natural is a term not well-defined in the report, the primary reason for stocking in these two cases is precisely because the stream is paradoxically not entirely natural, having undergone human disturbance.

Human impacts within the salmon environment (apart from the hatchery), although important parts of the overall salmon conservation discussion, seldom came up within discussions about how, why, or whether to use cultivation technologies to produce salmon. The exception was actually to justify stocking, in which report author Young described environments so damaged that wild salmon populations have ceased to exist and thus cannot be harmed by the introgression of hatchery-type salmon (NASCO 2017). Similarly, we also read that improving existing salmon habitat is (and should be) prioritized, inherently calling for human (artificial) interventions to improve functional ecosystems. These types of artificiality are acceptable within the report's conceptualizations of naturalness, indicating that some types of human interventions in salmon environments are acceptable whereas others are not. Thus, we understand that the mechanisms for deciding upon appropriate interventions are based on prioritizing biodiversity and functional salmon environments. Although an ecologically and scientifically sound approach to conservation, this prioritization tacitly implies that other priorities, such as social demands on salmon environments, are less justifiable reasons for human intervention in salmon lives.

\section{Salmonscapes on the ground: Wales}

Interpretations of naturalness from Welsh managers were embedded with the relevant salmon management statutes (see case background). Importantly, these statutes prioritize biodiversity and special protection for Atlantic salmon and its habitat in the River Wye. Concerned by the threat to biodiversity presented by hatchery-reared fish to wild stocks, managers view genetic naturalness as a priority issue by applying the precautionary principle (distinct from the precautionary approach), which disallows any activities that may risk the genetic integrity and biodiversity of Welsh salmon stocks. Because managers did not find sufficient new evidence during the publication consultation period to demonstrate a lack of harm (or acceptable level of risk), their 2014 decision to terminate stocking in Wales was presented in interviews as a straightforward and obvious step mandated by statutory duty (note: all names have been changed to protect the anonymity of interview participants):

We have statutory duties for maintaining, improving and developing fisheries for freshwater fish, migratory fish, and the eel. So, we have a duty to protect the fish stocks 
themselves as components of the environment and in many cases as features of designated sites (P. Simmons, June 16, 2016).

These duties are derived from regulations such as the Habitats Directive, for which the main aim is to:

\begin{abstract}
Promote the maintenance of biodiversity by requiring Member States to take measures to maintain or restore natural habitats and wild species listed on the Annexes to the Directive at a favourable conservation status, introducing robust protection for those habitats and species of European importance. In applying these measures Member States are required to take account of economic, social and cultural requirements, as well as regional and local characteristics (EEC 2000).
\end{abstract}

This is particularly relevant to the River Wye, which has been designated as a Special Area of Conservation (SAC) for the presence of Atlantic salmon in addition to several other highvalue species and topographical watershed features. However, the description of Atlantic salmon as a key species for conservation (EEC 2000, Annex II) remarks only on the qualities of the salmon and the unique population of multisea winter fish that occur in the Wye. The description does not say specifically why the River Wye salmon are valuable, nor in what context that value should be measured (i.e., cultural, economic, etc.). Thus, the way in which salmon are valued and therefore must be maintained is left up to interpretation from the Habitats Directive line: "Member States are required to take account of economic, social and cultural requirements, as well as regional and local characteristics" (EEC 2000).

As in the NASCO report, Wye managers utilize an interpretation of naturalness that categorizes human interventions into those which are acceptable (i.e., habitat improvement) and those which are not (i.e., hatcheries). How the practical categorization of activities is made is not explicitly clear, but it appears to depend on ecological and biological assessments on changes to the environment that can be concretely determined as a result of the conservation activity (i.e., improved water $\mathrm{pH}$, addition of gravel for spawning areas, etc.). Especially within the context of NASCO's guidance, this is a logical response on the part of managers because specific managerial goals are more realistic and achievable standards to which managers may set their sights. However, this position tacitly interpreted human intervention in the salmon reproductive and rearing processes as unnatural, and therefore damaging to the desired wild/natural salmon archetype. The Welsh decision to end stocking effectively removed humans from juvenile salmon life stages, therefore implying that salmon lives are more natural when set apart from human interaction or influence.

However, these strict interpretations of naturalness and nature were not shared by everyone in the case. Many stakeholders perceived the natural riverine environment to be something from a past age on the Wye, and that human influence remains inextricably a part of the River Wye landscape and, therefore, salmon. A Welsh fish biologist exemplified this conflict by saying:

I think we all agree that [habitat] going to be important, but I think sometimes the guys who are just pro-habitat and nothing else [...] feel that we can turn back the clock like 350 years and put everything back the way it was, and that's never ever going to happen. You'll never get rid of man-made impacts. It'll never be perfect. You can reduce them for sure but you can never get rid of them. It'll never go back to what it was (J. Daesh, June 16, 2016).

This comment indicates that not only are the characteristics that define naturalness in question, but also which time period represents the ideal natural salmon state and environment. This interpretation also disallowed for alternative conceptualizations of naturalness and human-salmon interventions that support human-salmon interactions aside from habitat improvement efforts.

In addition, there was little acknowledgement from managers about the ontological viewpoints of fisheries science and scientists, and whether these knowledge producers had alternative or underlying agendas (i.e., personal values, priorities) when contributing their knowledge to management policy. Within angling, river owner, and even scientific communities, however, people challenged the concept that science produces infallible knowledge free of ontological biases. For example, one scientist criticized underlying, perhaps unacknowledged, motivations within the scientific community:

I think that sometimes people believe [science is] not fallible. Well I think it is. I think recently genetics has been used against hatcheries pretty much every time you see it explained in the literature. And I think it hasn't been helpful. I personally think there has been a kind of an academic agenda amongst many geneticists to make a name for themselves. To be the first one to prove that hatchery fish definitely don't contribute better than wild [sic throughout] (J. Daesh, June 16, 2016).

These findings indicate that achieving a type of naturalness, although desirable to most managers and fisheries scientists, may not actually achieve the objectives of many stakeholders. Thus, the dominating conceptualizations of naturalness used on the Wye are not necessarily appropriate or accepted by all parties. For example, one stakeholder's comment about the value of interacting with salmon in a natural way, even if the salmon themselves are not wild-natural salmon:

\section{I don't think it really matters if that salmon doesn't have an adipose fin or it does if you see it jumping up on the weir. And maybe that's the way we have to have a balance in nature, not just pretend that everything can be the same that it was 300 years ago (J. Thompson, June 16, 2016).}

Salmonscapes on the ground: Norway

In Norway, managerial views of nature were quite similar to those reported in Wales, which is unsurprising because the managerial agencies in both countries draw from the same international guidelines and regulatory frameworks of NASCO and ICES. As much of the salmon habitat in the Ørsta River case remains relatively intact, managers promoted the utilization of available habitat as much as possible, though some human interventions, such as installing fish ladders, were considered acceptable (perhaps reflecting an overarching objective of the anthropogenic, rather than the salmonid, benefits of having natural salmon). As in Wales, the arbitrator of naturalness was the reproductive process of salmon and improving rearing 
habitat. Naturalness, in the case of reproduction, was described as an activity free of human interventions. For example:

\section{We [are] extending the natural habitat. That's something we do in order to increasing [sic] the number of fish that you can harvest, and have a bigger fishery. But then again, it's supposed to function by itself, you know. It's natural production (A. Lund, April 25, 2016).}

Norwegian managers also conceptualized the natural world as complex, complicated, and difficult to appropriately intervene in without causing incidental damage. They also separated humans from nature by describing processes within the natural world as processes that occur over nonhuman life scales (e.g., thousands of years) and must operate unimpeded by humans if they are to function correctly. For example:

We think there is a job to do to make them [anglers] understand that the nature is very complicated, and it's so much to take care of. It's invisible, invisible behavior systems taking care of the thousands of years selection, evolution, and so on (L. Larsen, May 11, 2016).

From this, we can see that managers view the Ørsta system as being nearly sufficient to provide all aspects required for salmon to thrive. Combined with views that human intervention in this otherwise effective natural system of salmon rearing is too complex to achieve without the risk of damage, it is unsurprising that managers in this case approach naturalness by removing human interventions, and thus humans, from the system. In effect, to do nothing, i.e., to eliminate active salmon cultivation, is viewed as a more sustainable approach than enacting risky cultivation schemes. As described by one manager:

\begin{abstract}
A very important key word: sustainable. Sustainable management of a river. Maybe the sustainable management of a river is [to] "do nothing," The river ecosystem is well-equipped for meeting all the needs of the different species. Here is our argument. There is suitable, original, naturally [sic] conditions for natural production. Thus, hatcheries are not necessary [sic throughout] (L. Larsen, May 11, 2016).
\end{abstract}

One further aspect illuminated by this statement is the complexity not only of the natural system, but also of the social-ecological systems in which salmon are embedded. The manager highlights the notion of sustainability, a complex term imbued with social, economic, and ecological meaning. Thus, the managers argument to do nothing and withdraw human technologies from nature attempts to reduce and manage both anthropogenic and ecological complexities, an apparent paradox in the current Anthropocene in which the intermingling of human and environmental systems is growing ever more complex.

Naturalness was also closely intertwined with ideals of wildness, which together construct the notion of the best fish. Characterized as a fish that can survive its life cycle without human intervention, this categorization of best fish suggests that hatchery-produced fish are deprived of the opportunity to evolve and struggle without human intervention (though, as before, apparently only in the context of reproduction and natural selection of juveniles). As described by one manager:
The finest and most precise nature product is a fish spawning for themselves in the rivers. And where Charles Darwin are working with them. And the smolts is a product of a tough freshwater period. It's the best fish [sic throughout] (L. Haugen, May 11, 2016).

In addition to humans being removed from salmon reproduction, it is also clear that human objectives and interests in the fishery are also invalidated if they conflict with natural events. For example, spring flooding in the Ørsta River occasionally rips up the streambed gravel and destroys reeds, particularly within the straightened section. This issue is of great concern to anglers and reinforces their beliefs that the hatchery is allowing them to compensate for natural events made abnormally destructive by the straightness of the river; in essence, the hatchery achieves naturalness previously damaged by human activity while simultaneously allowing anglers to achieve another important objective: angling opportunities. However, managers view the flooding as part of natural disasters in which hatcheries are artificial intrusions:

An often heard thought is every spring there is a spring
spate [flood]. The flow is so big [that] it turn[s] around
all the gravel and the living conditions in the rivers. [But]
here [for] ten thousand years, it has been a spring spate
every year. This is the way the nature is. So, these are
[the] natural machinery. We have to accept nature's
conditions. They are never fixed [sic throughout] (L.
Larsen, May 11, 2016).

This comment reflected the manager's view that interfering with natural processes to achieve human objectives, or even perhaps to compensate for past damage, is not an acceptable reason for intervention. This argument reinforces the view that removing humans from the salmon lifecycle remains a preferable managerial approach. However, it did not account for large-scale influence, such as the effects of climate change and other systemic, overarching changes occurring on a planetary scale with local impacts on salmon habitats, feed, and behavior.

Local anglers took a more pragmatic approach to preserving naturalness in their salmon rivers. From their perspective, naturalness and the idea of the wild salmon were desirable and, to some degree, still preferred in the peopled landscape around the Ørsta River. However, they viewed the attempt to achieve genetic naturalness as just one of many possible targets that could be achieved in salmon conservation. For example, they were greatly concerned with the marine environment being impacted by a whole host of unnatural challenges affecting migrating salmon (e.g., competition with escaped farmed salmon, dense biomass of sea lice, lack of prey for the migration smolt in the estuary and coastal habitats), but little attention being paid to these problems. As one angler explained:

They are afraid of the answer. Afraid to admit that the problem is in the ocean. And in the fjords (P. Magnus, May 3, 2016).

With these concerns in mind, anglers found it counterintuitive to refuse technologies that may help balance negative impacts on salmon that take place in both freshwater and marine environments. 


\section{DISCUSSION}

\section{Defining nature with new technologies}

This study shows that managers and scientists in these cases hold different and, at times, competing conceptualizations of nature and naturalness than those stakeholders engaged in hatchery work. Managers in both cases prioritize habitat improvement approaches over hatcheries to pursue salmon conservation work, citing the removal of human intervention from salmon reproductive and rearing processes as a way of reducing risk to the genetic integrity of wild salmon stocks. These arguments are underscored by international level stocking guidance produced by NASCO, which asserts a clear preference for minimizing hatchery technologies in a conservation context. These views are challenged by hatchery advocates who see the shift toward limiting, transforming, or removing humans from salmon lives as ignoring the many other problems that negatively affect adult salmon (e.g., pollution, angling pressures, etc.) and prioritizing naturalness over the pragmatic realities of the river environments in this study. Whereas fisheries scientists and most managers interviewed in both case studies view hatcheries as inappropriate technologies and subsequently have taken managerial steps to transform or limit the use of these facilities, angling and river owner stakeholders view hatchery technologies as a link between humans and natural salmon. These disparate views underlie conflict that surrounds both case studies in determining the role and appropriateness of hatchery technologies in wild salmon conservation.

We find that the nature of salmon invoked by the political debates and policy documents raises two paradoxes. First, as relationships between humans and salmon become increasingly complex and multimodal, managers are paradoxically seeking increasingly testable, defined, and limited means by which to define nature and best fish, resulting in the removal or limitation of human interventions (i.e., hatcheries) in salmon environments. This is clearly illustrated in the fieldwork in both Norway and Wales in which managers conceptualized naturalness as that which occurs in the absence of human intervention or manipulation thus setting humans and human action as opposite or otherwise apart from what is natural (Hepburn 1967).

Hatchery advocates, meanwhile, take a more constructed view of nature and comingle salmon and humans. This view, which includes humanity as part of nature, has been shared by others (Kormondy 1974, Jordan 1992, Rassler 1994, Turner 1994) and can be considered a nature-skeptical position (Soper 1998) in which the usefulness or possibility of separating natural from unnatural is questioned (Haydon 1997). Both cases were embedded in heavily peopled landscapes with long histories of human interactions with salmon via different technologies in which the hatchery has become an established means of performing human-salmon interactions. Thus, the line between humans as a part of nature and humans as alien to salmon lives and environments is blurred by the interactions within the hatchery.

The issue of technologies leads to the second paradox identified in this study: the managerial and scientific preference for a natural salmon has shifted from being qualitatively to genetically natural, a state that requires major technological efforts to be discovered in the first place. Thus, nature is technologically defined and required of technological intervention in salmon lives, even as some technologies are assessed as inappropriate means of facilitating human-salmon interactions. This selection of what is and is not an appropriate technology is a key bone of contention within these cases. Technologies, such as hatcheries, are embedded in technological systems that include people and organizations, known as socio-technological systems (Dwyer 2011). Technologies in these cases may be understood as a form of technological power (Lamont 1990) by allowing some groups to choose which technologies, and by extension the relationships they facilitate, are allowed and which are not. In that instance, the comingling of scientific, natural, and wildness conceptualizations have become the arbiters of determining appropriate technologies for salmon conservation and positions science as the only possible solution to all social and environmental problems (Haydon 1997). Many have critiqued this notion that technology can provide such limitless solutions, calling such notions the "fallacy of environmental control" (Relph 2015). By including and excluding certain technologies to achieve desired versions of nature, managers risk excluding their related social systems (people, organizations) as well.

\section{Overcoming the hatchery paradox}

In both cases, perceptions of nature were coupled with changing perceptions of the appropriateness of hatchery technologies in salmon conservation. In particular, the development of improved scientific knowledge strengthened managerial obligations to move away from the previously acceptable qualitatively natural salmon toward genetically natural salmon (Scarce 2000). This is unsurprising because conservation norms surrounding nature and naturalness fit well into the methodology of the natural sciences (Birnbacher 2014) and because of the inherent complexity of managing a socially and economically important species in a changing environment. This dependence on scientific knowledge and technology to determine the naturalness or wildness in salmon was not well-acknowledged by our study participants. This is important because it indicates a transition not only in how the scientific and conservationist communities view human-salmon relationships, but also in how the relationships themselves should be defined, measured, and controlled. In essence, technology, and how it is used to facilitate human-salmon relationships, becomes both friend and foe, necessary yet inappropriate.

Humans have been having an impact on the landscape in these cases for thousands of years, thus obscuring where the natural state ends and the unnatural state of human impacted nature begins (McKibben 2014). Within the ecosystem management framework, naturalness is generally defined as the preindustrial state within Europe (Hayes et al. 1987, Kilgore 1987). However, in the case of European salmon management, human influences dating from before industrialization have erased any definable concept of true naturalness (McKibben 2014), a view pointed out by pro-hatchery interview participants. Thus, in principle, there are no clear indicators as to where, or when, definitions about the state of naturalness in salmon or their environments can be made. Managers and salmon conservation interests are thus forced to construct demarcations of acceptable naturalness and, by extension, human-salmon relationships to contend with increasingly complex managerial obligations. 
Lavau (2011) pointed out that it is a resource and time intensive task for managers to establish and maintain boundaries between what species or environments are natural or wild, and therefore permissible, and those that are not. This follows a natureendorsing view, in which nature cannot practically be considered all-inclusive without becoming overwhelming (Wright 1992) and thus what is natural and unnatural must be divided along the lines of human action. From this, we argue that the empirical views of naturalness described in this study are constructed to be testable and achievable, and maintained as conceptualizations of nature in which humans and salmon are distinct and separate. Humanism separates humanity from nature via a cultural estrangement (Ehrenfeld 1978) in which humanity acts as an outside observer of nature and centers human-environmental relationships on human needs and values. This fits closely with the mandates of wild salmon managers, and thus their job is simplified if naturalness can be made testable and objectively achievable. Thus, we can look at arguments about the genetic impacts of hatcheryrearing on salmon in both cases to understand how highly technological approaches have been used to make naturalness a testable ideal. In both processes, only the salmon that are determined to be sufficiently free of human influence are considered to be appropriate for the production of future generations of wild salmon.

\section{Naturalness, for all?}

The findings and arguments in this study concerning conceptualizations of naturalness are not offered in condemnation of NASCO or country manager's adherence to biodiversity prioritization in salmon conservation policies. We understand that these priorities are based on what is considered best for the longevity and sustainability of threatened wild salmon stocks in both cases. Indeed, our objective in presenting these cases is to argue for a more nuanced perspective toward naturalness and best salmon, which may help explain the contentious nature of stocking debates. As stated in the Habitats Directive, the way in which salmon are valued or maintained must "take account of economic, social and cultural requirements, as well as regional and local characteristics" (EEC 2000). As such, we suggest that the conceptualizations of nature that, when operationalized, have resulted in the rejection of hatchery technologies be understood as contingently taking place in a techno-social sphere not shared by all stakeholder groups, thus resulting in conflict and frustration in both cases.

Though we agree that a focus on biodiversity and habitats is unquestionably an important priority for the longevity of wild salmon populations in both of these cases, we question whether disallowing some technologies wholesale without adequate replacement opportunities and using science as the only meaningful arbiter of what naturalness or wildness are (particularly when they can be known only through complex technologies) ultimately fail to account for how salmon are valued and maintained in local techno-societies. Similarly, we question whether naturalness should always be the ultimate goal, or whether more diversified strategies such as Sweden's river and fishery zoning system (Havs- och vattenmyndighetens 2015, Aas et al. 2018) might offer more appropriate solutions to localized challenge. As such, we argue that rather than moving toward stricter interpretations of nature as a means of reducing managerial complexity, conceptualizations of naturalness should remain disputable and human-salmon relationships and the technologies that support them should remain a priority in salmon management schemes.

Finally, this study demonstrates that both producers and implementers of empirical scientific knowledge in these cases hold specific, but often hidden ontologies related to naturalness and human-salmon interactions. The results suggest that managers and scientists are often unaware or unreflective of their ontological positions or beliefs, and thus are unable to account for or question the impact of personal values and social norms on natural resource management decisions or research (Moon and Blackman 2014). This lack of consideration has led to mismatched perceptions between stakeholder groups in both cases concerning how wild Atlantic salmon should be conserved and which technologies are appropriate in meeting conservation goals. Therefore, decision makers should reflect more carefully on the ontological baggage they bring to their research and regulatory positions, particularly when interpreting scientific data and implementing management decisions.

These two cases offer a lens by which to understand the divergence between increasingly complex and technology-driven salmon management that seeks to achieve specific scientific, social, and economic objectives, and the needs, objectives, and conceptualizations of local-level stakeholders and their humansalmon relationships. We identified how managers in both cases hold certain conceptualizations and manifestations of naturalness that allow them to achieve challenging and occasionally competing managerial goals by reducing complexity of these social-ecological systems, and how the process of defining nature and entangled natural salmon have become reliant on highly complex technologies. In this, relatively simple hatchery technologies and our more intuitive (or qualitative) relationships with salmon has been replaced with advanced genetic technologies that assert, define, and maintain a new definition of naturalness and human-salmon relationships (Scarce 2000, Birnbacher 2014). This shift within hatchery management has invalidated voluntary hatcheries as appropriate technologies, and in doing so has perhaps unintentionally begun to invalidate those stakeholders who are part of hatchery techno-social systems.

Within the Anthropocene, it is likely that change and the infiltration of human-driven artificiality will only become increasingly evident within salmon environments. As humans become inextricably mixed with nature via our technologies and influences, perhaps instead of attempting to identify specific definitions of a natural salmon, we should consider what habitats, characteristics, and interactions with humans and their institutions will be necessary for salmon to thrive in humansalmon environments in the future. To do so, managers and practitioners must not forget the valuable critiques that caution against one-size-fits-all solutions to natural resource problems (Campbell et al. 2006), and their collective plea for situated solutions that keep open degrees of freedom to incorporate local circumstances (Armitage 2005, Fujitani et al. 2017). To prevent these oversights, the fundamental ontologies managers and stakeholders adopt to support their salmon cultivation goals must be better understood, explicitly recognized, and then expanded to include and value multiple biological, ecological, and social objectives (Harrison et al. 2018a). 
Responses to this article can be read online at: http://www.ecologyandsociety.org/issues/responses. php/10945

\section{Acknowledgments:}

The authors thank Sophia Kochalski for her participation in fieldwork and data collection. Thanks also to N.O. Brekke for his translation services and proofreading, and to NINA staff for their transcription and translation help. The authors also thank all the scientists, fisheries managers and agencies, hatchery operators, anglers, and other stakeholders who took part in this research. Thanks also to Humboldt-Universität zu Berlin and IRI THESys and The Department of Geography for their support.

\section{LITERATURE CITED}

Aam, S. 2009. Lakseeventyret. Spor, Ulsteinvik, Norway.

Aas, Ø., J. Cucherousset, I. A. Fleming, C. Wolter, J. Höjesjö, M. Buoro, F. Santoul, J. I. Johnsson, K. Hindar, and R. Arlinghaus. 2018. Salmonid stocking in five North Atlantic jurisdictions identifying drivers and barriers to policy change. Aquatic Conservation: Marine and Freshwater Ecosystems 28: 1451-1464. https://doi.org/10.1002/aqc.2984

Araki, H., B. Cooper, and M. S. Blouin. 2007. Genetic effects of captive breeding cause a rapid, cumulative fitness decline in the wild. Science 318(5847):100-103. https://doi.org/10.1126/science.1145621

Araki, H., and C. Schmid. 2010. Is hatchery stocking a help or harm: evidence, limitations and future directions in ecological and genetic surveys. Aquaculture 308, Supplement 1:S2-S11. https:// doi.org/10.1016/j.aquaculture.2010.05.036

Arlinghaus, R., and T. Mehner. 2005. Determinants of management preferences of recreational anglers in Germany: habitat management versus fish stocking. Limnologica 35 (1-2):2-17. https://doi.org/10.1016/j.limno.2004.10.001

Armitage, D. 2005. Adaptive capacity and community-based natural resource management. Environmental Management 35 (6):703-715. https://doi.org/10.1007/s00267-004-0076-Z

Ban, N. C., M. Mills, J. Tam, C. C. Hicks, S. Klain, N. Stoeckl, M. C. Bottrill, J. Levine, R. L. Pressey, T. Satterfield, and K. M. A. Chan. 2013. A social-ecological approach to conservation planning: embedding social considerations. Frontiers in Ecology and the Environment 11(4):194-202. https://doi.org/10.1890/110205

Berg, M. 1986. Det norske laks- og innlandsfiskets historie. Fiskeetaten 1855-1986. [History of the development of Norwegian salmon- and inland fisheries. The Fishery Agency 1855-1986.] University Press of Norway, Oslo, Norway.

Berkes, F., J. Colding, and C. Folke. 2008. Navigating socialecological systems: building resilience for complexity and change. Cambridge University Press, Cambridge, UK. https://doi. org/10.1017/CBO9780511541957

Birnbacher, D. 2014. Naturalness: is the "natural" preferable to the "artificial"? University Press of America, Lanham, Maryland, USA.
Blanchet, S., D. J. Páez, L. Bernatchez, and J. J. Dodson. 2008. An integrated comparison of captive-bred and wild Atlantic salmon (Salmo salar): implications for supportive breeding programs. Biological Conservation 141(8):1989-1999. https://doi. org/10.1016/j.biocon.2008.05.014

Bottom, D. L. 1997. To till the water-a history of ideas in fisheries conservation. Pages 569-597 in D. J. Stouder, P. A. Bisson, and R. J. Naiman, editors. Pacific salmon and their ecosystems. Springer, New York, New York, USA. https://doi.org/10.1007/978-1-4615$\underline{-6375-4 \quad 31}$

Campbell, B. M., I. J. Gordon, M. K. Luckert, L. Petheram, and S. Vetter. 2006. In search of optimal stocking regimes in semi-arid grazing lands: one size does not fit all. Ecological Economics 60 (1):75-85. https://doi.org/10.1016/j.ecolecon.2006.05.010

Chilcote, M. W., K. W. Goodson, and M. R. Falcy. 2011. Reduced recruitment performance in natural populations of anadromous salmonids associated with hatchery-reared fish. Canadian Journal of Fisheries and Aquatic Sciences 68(3):511-522. https://doi. org/10.1139/f10-168

Convention on Biological Diversity. 1995. Conference of the Parties (COP) 5 decision VI6: ecosystem approach. Convention on Biological Diversity, Rio de Janeiro, Brazil. [online] URL: https://www.cbd.int/decision/cop/default.shtml?id=7148

Cronon, W. 1995. Uncommon ground: toward reinventing nature. W. W. Norton and Company, New York, New York, USA.

Daniels, J., and C. Mather. 2017a. Conserving Atlantic salmon 'after nature' on Newfoundland's Gander River. BJHS Themes 2:191-213. https://doi.org/10.1017/bjt.2016.15

Daniels, J., and C. Mather. 2017b. Conservation and care: material politics and Atlantic salmon on Newfoundland's Gander River. Maritime Studies 16:17. https://doi.org/10.1186/s40152-017-0072-6

Dwyer, C. 2011. Socio-technical systems theory and environmental sustainability. Sprouts: Working Papers on Information Systems 11(3):9.

Ehrenfeld, D. 1978. The arrogance of humanism. Oxford University Press, New York, New York, USA.

European Economic Community (EEC). 2000. Council Directive 92/43/EEC of 21 May 1992 on the conservation of natural habitats and of wild fauna and flora. European Economic Community, Brussels, Belgium. [online] URL: https://eur-lex.europa.eu/eli/ dir/1992/43/oj

Evans, J., and P. Jones. 2011. The walking interview: methodology, mobility and place. Applied Geography 31(2):849-858. https://doi. org/10.1016/j.apgeog.2010.09.005

Foote, C. J. 1988. Male mate choice dependent on male size in salmon. Behaviour 106(1):63-80. https://doi.org/10.1163/156853$\underline{\text { 988X00098 }}$

Fujitani, M., A. McFall, C. Randler, and R. Arlinghaus. 2017. Participatory adaptive management leads to environmental learning outcomes extending beyond the sphere of science. Science Advances 3(6):e1602516. https://doi.org/10.1126/sciadv.1602516

Garcia de Leaniz, C., I. A. Fleming, S. Einum, E. Verspoor, W. C. Jordan, S. Consuegra, N. Aubin-Horth, D. Lajus, B. H. Letcher, 
A. F. Youngson, J. H. Webb, L. A. Vøllestad, B. Villanueva, A. Ferguson, and T. P. Quinn. 2007. A critical review of adaptive genetic variation in Atlantic salmon: implications for conservation. Biological Reviews 82(2):173-211. https://doi. org/10.1111/j.1469-185X.2006.00004.X

Gilbert, H. A. 1929. The tale of a Wye fisherman. Methuen and Co. Ltd., London, UK.

Harrison, H. L., S. Kochalski, R. Arlinghaus, and Ø. Aas. $2018 a$. "Nature's little helpers": a benefits approach to voluntary cultivation of hatchery fish to support wild Atlantic salmon (Salmo salar) populations in Norway, Wales, and Germany. Fisheries Research 204:348-360. https://doi.org/10.1016/j. fishres.2018.02.022

Harrison, H. L., S. Kochalski, R. Arlinghaus, and Ø. Aas. 2019. "Do you care about the river?" A critical discourse analysis and lessons for management of social conflict over Atlantic salmon (Salmo salar) conservation in the case of voluntary stocking in Wales. People and Nature, in press.

Harrison, H. L., S. Rybråten, and Ø. Aas. 2018b. Hatching knowledge: a case study on the hybridization of local ecological knowledge and scientific knowledge in small-scale Atlantic salmon (Salmo salar) cultivation in Norway. Human Ecology 46 (4):449-459. https://doi.org/10.1007/s10745-018-0001-3

Havs- och vattenmyndighetens. 2015. Förvaltning av lax och öring Havs- och vattenmyndighetens förslag på hur förvaltning av lax och öring bör utformas och utvecklas. Havs- och vattenmyndighetens, Göteborg, Sweden.

Haydon, R. 1997. The concept of naturalness in natural resource and ecosystem management. Central Washington University, Ellensburg, Washington, USA.

Hayes, T. D., D. H. Riskind, and W. L. Pace, III. 1987. Patchwithin-patch restoration of man-modified landscapes within Texas State Parks. Pages 173-198 in Landscape heterogeneity and disturbance. Springer, New York, New York, USA. https://doi. org/10.1007/978-1-4612-4742-5 10

Hendee, J. C., G. H. Stankey, and R. C. Lucas. 1978. Wildlife management. U.S. Department of Agriculture, Washington, D. C., USA.

Henderson, J. N., and B. H. Letcher. 2003. Predation on stocked Atlantic salmon (Salmo salar) fry. Canadian Journal of Fisheries and Aquatic Sciences 60(1):32-42. https://doi.org/10.1139/ $\underline{\mathrm{f03}-001}$

Hepburn, R. W. 1967. Nature, philosophical ideas of. Pages 454-458 in Encyclopedia of philosophy. Macmillan, New York, New York, USA.

Hewlett, N. R., J. Snow, and J. R. Britton. 2009. The role of management practices in fish kills in recreational lake fisheries in England and Wales. Fisheries Management and Ecology 16 (3):248-254. https://doi.org/10.1111/j.1365-2400.2009.00671.x

Hurley, H. 2008. Landscape origins of the Wye Valley. Logaston, Hereforeshire, UK.

Jonsson, B., and N. Jonsson. 2006. Cultured Atlantic salmon in nature: a review of their ecology and interaction with wild fish.
ICES Journal of Marine Science 63(7):1162-1181. https://doi. org/10.1016/j.icesjms.2006.03.004

Jordan, A., and T. O'Riordan. 1995. The precautionary principle in UK environmental law and policy. Pages 57-84 in Tim S. Gray, editor. UKenvironmental policy in the 1990s. Palgrave Macmillan, London, UK. https://doi.org/10.1007/978-1-349-24237-5 5

Jordan, W. R. 1992. Otro mundo restoration, Columbus, and the search for Eden. Ecological Restoration 10(1):3. https://doi. org/10.3368/er.10.1.3

Kilgore, B. M. 1987. The role of fire in wilderness: a state-ofknowledge review. Pages 70-103 in R. C. Lucas, editor. Proceedings of the national wilderness research conference: sssues, state-of-knowledge, future directions. US Forestry Service, Washington, D.C., USA.

Kormondy, E. J. 1974. Natural and human ecosystems. Human Ecology :27-43.

Kusenbach, M. 2003. Street phenomenology: the go-along as ethnographic research tool. Ethnography 4(3):455-485. https:// doi.org/10.1177/146613810343007

Laikre, L., M. K. Schwartz, R. S. Waples, and N. Ryman. 2010. Compromising genetic diversity in the wild: unmonitored largescale release of plants and animals. Trends in Ecology and Evolution 25(9):520-529. https://doi.org/10.1016/j.tree.2010.06.013

Lamont, C. 1990. The philosophy of humanism. 6th revised. Continuum, New York, New York, USA.

Landry, C., D. Garant, P. Duchesne, and L. Bernatchez. 2001. 'Good genes as heterozygosity': the major histocompatibility complex and mate choice in Atlantic salmon (Salmo salar). Proceedings of the Royal Society of London B: Biological Sciences 268(1473):1279-1285. https://doi.org/10.1098/rspb.2001.1659

Lavau, S. 2011. The nature/s of belonging: performing an authentic Australian River. Ethnos 76(1):41-64. https://doi. org $/ 10.1080 / 00141844.2010 .537758$

Lorenzen, K., A.-L. Agnalt, H. L. Blankenship, A. H. Hines, K. M. Leber, N. R. Loneragan, and M. D. Taylor. 2013. Evolving context and maturing science: aquaculture-based enhancement and restoration enter the marine fisheries management toolbox. Reviews in Fisheries Science 21(3-4):213-221. https://doi. org/10.1080/10641262.2013.837358

Marshall, M. N. 1996. The key informant technique. Family Practice 13(1):92-97. https://doi.org/10.1093/fampra/13.1.92

McKibben, B. 2014. The end of Nature. Random House, New York, New York, USA.

Meffe, G. K. 1992. Techno-arrogance and halfway technologies: salmon hatcheries on the Pacific coast of North America. Conservation Biology 6(3):350-354. https://doi.org/10.1046/ j.1523-1739.1992.06030350.x

Mes, D. 2018. Effects of the hatchery environment on neurobiology and behaviour in Atlantic salmon: implications for stocking. Dissertation. Norwegian University of Life Sciences, As, Norway. 
Milton, K. 2000. Ducks out of water. In J. Knight, editor. Natural enemies: people-wildlife conflicts in anthropological perspective. Routledge, London, UK.

Moon, K., and D. Blackman. 2014. A guide to understanding social science research for natural scientists. Conservation Biology 28(5):1167-1177. https://doi.org/10.1111/cobi.12326

Naish, K. A., J. E. Taylor, III, P. S. Levin, T. P. Quinn, J. R. Winton, D. Huppert, and R. Hilborn. 2007. An evaluation of the effects of conservation and fishery enhancement hatcheries on wild populations of salmon. Advances in Marine Biology 53:61-194. https://doi.org/10.1016/S0065-2881(07)53002-6

North Atlantic Salmon Conservation Organization (NASCO). 2006. NASCO guidelines on the use of stock rebuilding programmes in the context of the precautionary management of salmon stocks. Council Report. North Atlantic Salmon Conservation Organization, Edinburgh, Scotland.

North Atlantic Salmon Conservation Organization (NASCO). 2007. Resolution by the parties to the convention for the conservation of salmon in the North Atlantic Ocean to minimise impacts from aquaculture, introductions and transfers, and transgenics on the wild salmon stocks. North Atlantic Salmon Conservation Organization, Edinburgh, Scotland. [online] URL: http://www.nasco.int/pdf/agreements/williamsburg.pdf

North Atlantic Salmon Conservation Organization (NASCO). 2017. Understanding the risks and benefits of hatchery and stocking activities to wild Atlantic salmon populations. NASCO Council Document. North Atlantic Salmon Conservation Organization, Varberg, Sweden.

Norwegian Environment Agency. 2014. Guidelines for stocking of anadromous salmoniods. In Norwegian: Retningslinjer for utsetting av anadrom fisk. Norwegian Environment Agency, Trondheim, Norway.

QSR International Pty Ltd. 2012. NVivo qualitative data analysis software. QSR International Pty Ltd., Doncaster, Australia.

Palys, T. 2008. Purposive sampling. Pages 697-698 in L. M. Niven, editor. The Sage encyclopedia of qualitative research methods. Sage, Thousand Oaks, California, USA.

Paquet, P. J., T. Flagg, A. Appleby, J. Barr, L. Blankenship, D. Campton, M. Delarm, T. Evelyn, D. Fast, J. Gislason, P. Kline, D. Maynard, L. Mobrand, G. Nandor, P. Seidel, and S. Smith. 2011. Hatcheries, conservation, and sustainable fisheriesachieving multiple goals: results of the hatchery scientific review group's Columbia River Basin review. Fisheries 36(11):547-561. https://doi.org/10.1080/03632415.2011.626661

Paulus, T. M., and J. N. Lester. 2016. ATLAS.ti for conversation and discourse analysis studies. International Journal of Social Research Methodology 19(4):405-428. https://doi. org/10.1080/13645579.2015.1021949

Rassler, S. 1994. Naturalness and anthropocentricity. Restoration and Management Notes 12(2):116-117.

Relph, E. 2015. Rational landscapes and humanistic geography. Routledge, New York, New York, USA. https://doi. org/10.4324/9781315672601
Scarce, R. 2000. Fishy business: salmon, biology, and the social construction of Nature. Temple University Press, Philadelphia, Pennsylvania, USA.

Scientific Software Development. 1999. ATLAS.ti. Scientific Software Development, Berlin, Germany. [online] URL: https:// atlasti.com/product/technical-info/

Soper, K. 1998. What is Nature: culture, politics and the nonhuman. Environmental Values 7(3):360-361.

Stensland, S. 2012. Typology of landowners in Norwegian salmon angling: attitudes towards river owner organisations and management actions. Fisheries Management and Ecology 19 (4):273-282. https://doi.org/10.1111/j.1365-2400.2011.00829.x

Svåsand, T., A.-L. Agnalt, O. T. Skilbrei, J. Borthen, and T. Heggberet. 2004. An integrated development program for marine stocking: the Norwegian example. Pages 19-72 in D. M. Bartley and K. M. Leber, editors. Marine ranching. Food and Agriculture Organization, Rome, Italy. [online] URL: http://www.fao.org/3/ y4783e/y4783e03.pdf

Swain, D. P., and B. E. Riddell. 1990. Variation in agonistic behavior between newly emerged juveniles from hatchery and wild populations of Coho salmon, Oncorhynchus kisutch. Canadian Journal of Fisheries and Aquatic Sciences 47(3):566-571. https:// doi.org/10.1139/f90-065

Turner, F. 1994. The invented landscape. Pages 35-66 in A. D. Baldwin, J. de Luce, and C. Pletsch, editors. Beyond preservation: restoring and inventing landscapes. University of Minnesota Press, Minneapolis, Minnesota, USA.

Watters, J. V. 2005. Can the alternative male tactics 'fighter' and 'sneaker' be considered 'coercer' and 'cooperator' in Coho salmon? Animal Behaviour 70(5):1055-1062. https://doi. org/10.1016/j.anbehav.2005.01.025

Wolter, C. 2015. Historic catches, abundance, and decline of Atlantic salmon Salmo salar in the River Elbe. Aquatic Sciences 77(3):367-380. https://doi.org/10.1007/s00027-014-0372-5

Wright, W. 1992. Wild knowledge: science, language, and social life in a fragile environment. University of Minnesota Press, Minneapolis, Minnesota, USA. 